\title{
AVALIAÇÃO DOS TEORES DE ALUMÍNIO EM ANTITRANSPIRANTES
}

\section{EVALUATION OF ALUMINUM CONTENT IN ANTIPERSPIRANTS}

\author{
Débora Regina Lopes ${ }^{1}$; Maurício Augusto de Oliveira ${ }^{1}$; Daniel Ângelo \\ Macena'; Vinícius Marques Gomes ${ }^{1}$. \\ ${ }^{1}$ Universidade do Oeste Paulista, Curso de Química Bacharelado, Presidente Prudente, \\ São Paulo. \\ e-mail: viniciusmarques@unoeste.br
}

RESUMO - O antitranspirante funciona através da difusão do sal de alumínio pelos ductos das glândulas sudoríparas na abertura da epiderme. Após contato com o suor da transpiração, é produzido um complexo mucopolissacarídeo que reduz a transpiração. Quando seu teor está alto no sangue, os ossos o capturam e o liberam lentamente causando assim distrofia óssea. O objetivo deste projeto foi determinar os teores de alumínio no antitranspirante, de marcas distintas comercializadas em supermercados, e verificar se as concentrações estão de acordo com o rótulo e em conformidade com a legislação. Foi utilizado o método de titulação complexométrica. Das três marcas analisadas, a primeira não apresentou alumínio, importante para o efeito antitranspirante, a segunda continha quantidades inferiores ao informado no rótulo e a terceira apresentou teores acima do permitido pela legislação. Portanto, nenhuma das marcas analisadas apresentou resultados positivos.

Palavras-chave: antitranspirantes; alumínio; tóxico; saúde.

Recebido em: 25/05/2018

Revisado em: 22/08/2018

Aprovado em: 02/09/2018
ABSTRACT - The antiperspirant works by diffusing the aluminum salt through the ducts of the sweat glands into the opening of the epidermis. After contact with perspiration sweat, a mucopolysaccharide complex is produced that reduces perspiration. When its content is high in blood, the bones capture and release it slowly causing bone dystrophy. The objective of this project was to determine the levels of aluminum in the antiperspirant, of different brands marketed in supermarkets, and to verify if the concentrations are in agreement with the label and in accordance with the legislation. The complexometric titration method was used. Of the three brands analyzed, the first one did not present aluminum, important for the antiperspirant effect, the second one contained lower amounts than the one informed on the label and the third one presented levels above that allowed by the legislation. Therefore, none of the analyzed brands presented positive results.

Keywords: antiperspirants; aluminum; toxic; health. 


\section{INTRODUÇÃO}

O cloreto de alumínio foi à primeira substância utilizada como antitranspirante que apresentou uma boa ação. Porém, causava irritações na pele e mancha nos tecidos. Por isso, vem sendo substituído pelos sais hidratados de cloreto de alumínio, os cloridratos de alumínio (formula geral $\mathrm{Al}_{n} \mathrm{Cl}_{(3 n-m)}(\mathrm{OH})_{m}$, que não apresentam esses inconvenientes. Um exemplo é o sesquicloridróxido de alumínio, que apresenta baixo grau de irritação, sendo indicado para produtos hipoalergênicos (GARRET, 2010).

O antitranspirante funciona através da difusão do sal de alumínio pelos ductos das glândulas sudoríparas na abertura da epiderme, que é a camada superior da pele. Após contato com o suor da transpiração, é produzido um gel ou complexo mucopolissacarídeo que obstrui os ductos impedindo a saída do suor pela pele (GARRET, 2010).

Alguns antitranspirantes também contêm desodorantes. Os desodorantes não previnem o suor, mas podem reduzir o número de bactérias e diminuir o odor (GARRET, 2010).

Há diversos estudos que objetivam a determinação do agente mais efetivo, mas, por enquanto, compostos de Alumínio e de Zircônio são os mais utilizados na formulação de antitranspirantes, sendo o cloreto de alumínio hexaidratado $\left(\mathrm{AlCl}_{3} \bullet 6 \mathrm{H}_{2} \mathrm{O}\right)$ um dos antitranspirantes mais efetivos (CHARLET, 1996 appud NASCIMENTO et al. 2004).

Segundo a ANVISA (2000) o limite máximo de concentração em base anidra de formulação de $15 \%$.

O Brasil é o primeiro país do mundo em consumo de antitranspirantes e desodorantes. $O$ índice de penetração deste tipo de produto no país chega a atingir $87 \%$ dos brasileiros (RIBEIRO, 2015).

Segundo ABIHPEC (2015) os desodorantes e antitranspirantes são os mais utilizados no mercado brasileiro, o que tem sido uma busca de melhorias por partes da empresa encarecendo os produtos a fim de poder ter um diferencial e preferência na hora da compra.

Uma vez absorvido pela pele, o metal contido nos desodorantes pode ter efeitos tóxicos, causando respostas alérgicas, como dermatite e urticária de contato diverso. Os consumidores estão alheios aos seus possíveis riscos, incentivando a realização de mais pesquisas sobre essa temática (RIBEIRO, 2015).

Durante muito tempo, o alumínio foi considerado inofensivo à saúde humana, mas a partir da década de 1970, informações divergentes sobre a segurança do uso de derivados de alumínio vêm sendo veiculadas, tanto na grande mídia, como em artigos científicos. Pesquisadores iniciaram estudos que relacionavam 0 alumínio com 0 desenvolvimento de patologias, tais como a doença de Alzheimer (DA) e o câncer de mama com a ação toxicológica do alumínio (FERREIRA et al., 2008).

Este estudo foi realizado com o intuito de determinar os teores de alumínio presentes em antitranspirantes das marcas distintas comercializadas em supermercados e verificar se tais concentrações estão de acordo com o especificado no rótulo do produto e se estão dentro dos valores máximos permitidos conforme recomendado pela legislação.

\section{MÉTODO}

As análises foram realizadas nos laboratórios de Química, localizados no Bloco Q, da Universidade do Oeste Paulista UNOESTE de Presidente Prudente, Estado de São Paulo.

As amostras foram adquiridas em estabelecimentos da cidade de Presidente Prudente. Em princípio, foram selecionadas três marcas de antitranspirantes (marca $X, Y$ e Z) submetidas às análises de caráter qualitativo e quantitativo. Foram analisados três lotes diferentes de cada marca.

$\mathrm{Em}$ um béquer de $150 \mathrm{~mL}$ adicionouse $0,2 \mathrm{~g}$ de amostra (precisão de 0,1 mg) e 


\section{colloquium exactarum}

$100 \mathrm{~mL}$ de água deionizada; aqueceu-se o sistema sob agitação magnética até dissolução, e a solução foi transferida para balão volumétrico de $250 \mathrm{~mL}$, completandose o volume.

Em uma alíquota de $25,00 \mathrm{~mL}$ em erlenmeyer de $250 \mathrm{~mL}$, adicionou-se $4,0 \mathrm{~mL}$ da solução de EDTA e 15,00 mL da solução de amônio tampão $\mathrm{pH} 10$ utilizando-se fita de indicador universal para verificar o pH 10. Para assegurar à completa complexação do alumínio, a mistura foi colocada sobre uma chapa de aquecimento por 5 minutos. Deixou-se esfriar e adicionou-se mais 15,00 $\mathrm{mL}$ da solução tampão.

O EDTA forma complexo com os íons metálicos na proporção 1:1 independentemente da carga dos íons e sua estabilidade está estritamente relacionada aos vários sítios ativos presentes na sua molécula que formam quelatos, onde isolam o íon metálico da solução (SKOOG, 2005).

FIGURA 1. Fluxograma da titulometria por excesso para determinação de alumínio.

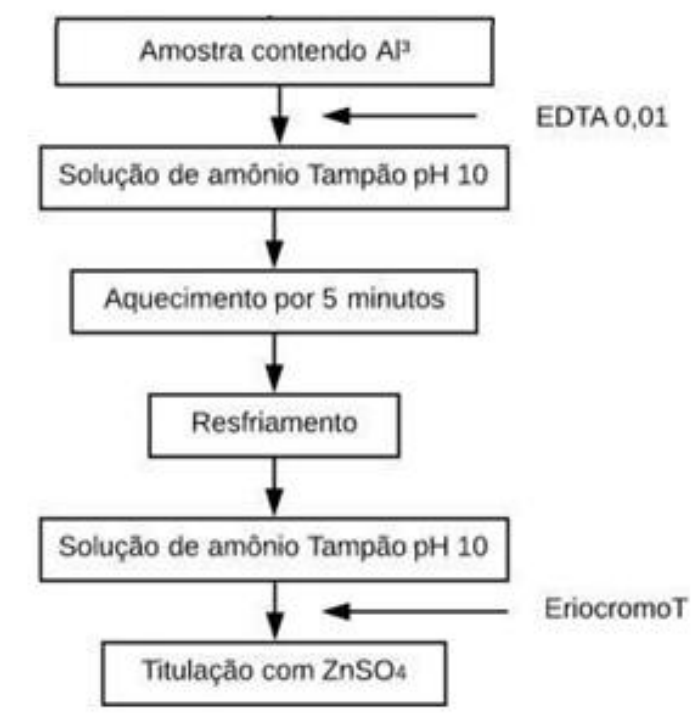

Fonte: Próprio autor.

Com uma ponta de espátula colocouse o indicador eriocromo $T$ até obter um azul claro, e a solução foi titulada com solução padrão de sulfato de zinco $0,01 \mathrm{~mol} / \mathrm{L}$, até que a cor azul claro mudasse para a cor roxa.

A quantidade de alumínio, em $\mathrm{mg}$, foi calculada pela expressão:
$\mathrm{Al}(\mathrm{mg})=\left(-\mathrm{V}_{\text {EDTA }}(\mathrm{mL})-\mathrm{V}_{\mathrm{t}}(\mathrm{mL})\right) \times 2,698$

Sendo $V_{t}=$ volume da solução de sulfato de zinco $V_{\text {EDTA }}=$ volume da solução de EDTA adicionado.

O procedimento foi realizado em triplicata segundo a FIGURA 1 (VOGEL, 2002; BATISTA et al., 2010).

A ANVISA determina que o valor máximo permitido para alumínio em antitranspirantes seja de $15 \%$.

\section{RESULTADOS}

As amostras foram tratadas e analisadas pelo método conhecido como retrotitulação, já que o Al não pode ser determinado diretamente, pois reage muito lentamente com EDTA. Utilizou-se o reagente dissódico do EDTA devido a sua alta solubilidade em água. Para a análise, usou-se um excesso de EDTA na solução contendo o analito, onde seu excesso foi titulado com $\mathrm{ZnSO}_{4}$, e o ponto final foi identificado pelo indicador metalocrômico negro de Eriocromo $\mathrm{T}$, formando uma reação reversível entre o $\mathrm{Al}$ e o indicador, tendo como produto da reação é um complexo instável. A utilização da solução tampão é para aumentar a estabilidade do complexo, pois o EDTA é estável em pH alcalino (VOGEL, 2002).

Para a Marca $X$ foram obtidos os valores apresentados na TABELA 1:

TABELA 1. Resultados para Marca X.

\begin{tabular}{c|c}
\hline \multicolumn{2}{c}{ Marca $\mathbf{X}$} \\
\hline Massa da amostra (g) & $\mathbf{V}_{\mathbf{Z n S O 4}}(\mathbf{m L})$ \\
\hline 0,2166 & 4 \\
\hline 0,2064 & 4 \\
\hline 0,2385 & 4 \\
\hline Média: 0,2205 & Média: 4 \\
\hline
\end{tabular}

Fonte: próprio autor.

Para a Marca $\mathrm{Y}$ foram obtidos os valores apresentados na TABELA 2: 
colloquium exactarum

TABELA 2. Resultados para Marca Y.

Marca Y

\begin{tabular}{c|c}
\hline Massa da amostra $(\mathbf{g})$ & $\mathbf{V}_{\mathbf{Z n S O} 4}(\mathbf{m L})$ \\
\hline 0,2400 & 3,6 \\
\hline 0,2183 & 3,6 \\
\hline 0,2346 & 3,6 \\
\hline Média: 0,2310 & Média: 3,6 \\
\hline
\end{tabular}

Fonte: próprio autor.

Para a Marca Z foram obtidos os valores apresentados na TABELA 3:

TABELA 3. Resultados para Marca Z.

\begin{tabular}{c|c}
\hline \multicolumn{2}{c}{ Marca Y } \\
\hline Massa da amostra $(\mathrm{g})$ & $\mathrm{V}_{\text {Znso4 }}(\mathrm{mL})$ \\
\hline 0,2089 & 2,3 \\
\hline 0,2201 & 2,3 \\
\hline 0,2531 & 2,3 \\
\hline Média: 0,2274 & Média: 2,3 \\
\hline
\end{tabular}

Fonte: próprio autor.

\section{DISCUSSÃO}

Segundo ANVISA (2001), os componentes devem estar ordenados em no rótulo pela abundância do maior para o menor.

A composição do produto da Marca $X$ segundo o rótulo seria: Água, Cloridrato de Alumínio, Éter Estearílico Polipropilenoglicol15, Steareth-21, Extrato de Flor Chamomilla Recutita, Bisabolol, Óleo de Persea Gratissima, Óleo de Soja Glicina, EDTA Trissódico. No rótulo do produto, o alumínio é apresentado como o segundo composto em abundância.

Pelos resultados, a amostra não apresentou teor de alumínio significativo, mesmo sendo ele o princípio ativo do antitranspirante e ser o segundo elemento mais abundante de acordo com o rótulo da marca.

A composição do produto da Marca $Y$ segundo o rótulo seria: Água, cloridróxido de alumínio, helianthus annuus (óleo de semente de girassol), glicerina, Polietilenoglicol-2 estearil éter,
Polietilenoglicol-20 estearil éter, EDTA dissódico, hidroxitolueno butilado.

Neste caso, a marca também apresenta o alumínio como o segundo elemento mais abundante.

A marca analisada apresentou teor de alumínio em torno de 5\%, portanto abaixo do valor determinado pela legislação. Sabendo que o alumínio é o princípio ativo do antitranspirante, isso influi diretamente na eficácia do produto já que a marca em questão apresentou um efeito menor de tamponamento da transpiração, principalmente em um país com o clima tão elevado quanto o Brasil.

A composição do produto da Marca Z segundo o rótulo seria: Água, cloridróxido de alumínio, Polipropilenoglicol-15 estearil éter, Polietilenoglicol-2 estearil éter, Polietilenoglicol-20 estearil éter, EDTA, dissódico, hidroxitolueno butilado.

Da mesma forma, a marca $Z$ também apresenta o alumínio como o segundo elemento mais abundante.

De acordo com os resultados, a Marca $Z$ apresentou teores de alumínio em torno de $20 \%$, portanto acima do limite permitido pela legislação brasileira, podendo ocasionar respostas alérgicas e manchas nos tecidos das roupas dos consumidores.

\section{CONSIDERAÇÕES FINAIS}

Conclui-se que a marca $X, Y$ e $Z$, obtiveram valores bem distinto. $O$ antitranspirante da Marca $X$, que trazia em suas informações de composição o alumínio como o segundo componente mais abundante, após análise de três lotes diferentes em triplicata, verificou-se que não existia teores significativos de alumínio em sua composição. Como o alumínio é o princípio ativo que induz um menor fluxo da transpiração, os consumidores estão pagando por um produto que não trará o resultado esperado para um antitranspirante.

A marca $Y$ apresentou teores de abaixo do recomendado pela legislação. Portanto, conclui-se que a marca analisada 


\section{colloquium exactarum}

pode ser ineficaz devido à quantidade inferior do princípio ativo, considerando o clima e a temperatura elevada no país, podendo ser um produto economicamente não viável aos consumidores brasileiros.

A Marca $Z$ foi a que apresentou o maior teor de alumínio em sua composição, no entanto, acima do máximo permitido pela legislação brasileira e podendo causar reações alérgicas e manchas nos tecidos das roupas.

Desta forma, conclui-se que nenhuma das três marcas analisadas apresentou teores satisfatórios de alumínio em sua composição, já que a marca $X$ não continha alumínio, a marca $Y$ apresentou quantidade inferior ao ideal e a marca $Z$ continha teores acima doSKO permitido pela legislação.

\section{REFERÊNCIAS}

ABIHPEC - ASSOCIAÇÃO BRASILEIRA DA INDÚSTRIA HIGIENE PESSOAL PERFUMARIA ECOSMÉTICOS. Setor brasileiro de Higiene Pessoal, Perfumaria e Cosméticos sofre queda real de 8\% em 2015.

ANVISA. Resolução RDC no 79, de 28 de agosto de 2000. Brasília, 2000.

ANVISA. Parecer técnico sobre o uso de antitranspirantes e sua relação com o câncer de mama. Brasília, 04 de julho de 2001.

BATISTA et al. Teor de alumínio em antitranspirantes disponíveis no comércio de Muriaé-Mg. In: CONGRESSO BRASILEIRO DE QUÍMICA, 50, 2010, Cuiabá. Anais eletrônicos... Cuiabá: Agroindústria, Qualidade de vida e Biomas Brasileiros. 2010.

FERREIRA, et al. Alumínio como fator de risco para Alzheimer. Rev Latino-am Enfermagem, Ribeirão Preto, v.16, n.1, p.71-82, 2008.
$<$ http://qnint.sbq.org.br/novo/index.php?has h=molecula.377>. Acesso em: 19 ago. 2017.

NASCIMENTO, et al.Aspectos atuais sobre a segurança no uso de produtos antiperspirantes contendo derivados de alumínio. 2004. 72f. Trabalho de conclusão de Curso (Pós graduação)- Universidade Federal do Rio Grande do Sul, Porto Alegre, 2004.

RIBEIRO, C. J. Comestologia aplicada a Dermoestética. 2. Ed. São Paulo: Editora Pharmabooks, 2015 p.53-73.

SKOOG.Fundamentos de química analítica quantitativa. 8. ed. São Paulo: Thomson, 2005.

VOGEL, A. I. Análise química quantitativa. 6. ed. Rio de Janeiro: LTC, 2002.

\section{GARRETT, R. Cloreto de alumínio, AlCl3.

